This item was submitted to Loughborough's Research Repository by the author.

Items in Figshare are protected by copyright, with all rights reserved, unless otherwise indicated.

\title{
Retardation effects due to overloads in aluminium-alloy aeronautical components
}

PLEASE CITE THE PUBLISHED VERSION

http://dx.doi.org/10.1111/ffe.12591

PUBLISHER

(c) Wiley

VERSION

AM (Accepted Manuscript)

\section{PUBLISHER STATEMENT}

This work is made available according to the conditions of the Creative Commons Attribution-NonCommercialNoDerivatives 4.0 International (CC BY-NC-ND 4.0) licence. Full details of this licence are available at: https://creativecommons.org/licenses/by-nc-nd/4.0/

\section{LICENCE}

CC BY-NC-ND 4.0

\section{REPOSITORY RECORD}

Maligno, Angelo R., R. Citarella, and Vadim V. Silberschmidt. 2019. "Retardation Effects Due to Overloads in Aluminium-alloy Aeronautical Components". figshare. https://hdl.handle.net/2134/24683. 


\title{
Retardation effects due to overloads in aluminium- alloy aeronautical components
}

\author{
A. R. MALIGNO ${ }^{1}$, R. CITARELLA ${ }^{2}$ and V. V. SILBERSCHMIDT ${ }^{3}$ \\ ${ }^{1}$ Institute for Innovation in Sustainable Engineering, University of Derby, Derby DE1 3HD, UK, ${ }^{2}$ Department of Industrial Engineering, University of \\ Salerno, Fisciano, SA Italy, ${ }^{3}$ Wolfson School of Mechanical and Manufacturing Engineering, Loughborough University, Loughborough, UK
}

\begin{abstract}
A B S TRA C T Fatigue data are generally derived under constant-amplitude loading conditions, but aircraft components are subjected to variable-amplitude loading. Without interaction effects, caused by overloads and underloads intermingled in a loading sequence, it could be relatively easy to establish a crack growth curve by means of a cycle-by-cycle integration. However, load-spectrum effects largely complicate a crack growth under variableamplitude cycling. In this paper, fatigue crack growth behaviour of aeronautical aluminium alloy 2024-T3 was studied. Effects of various loading conditions such as stress ratio and amplitude loadings were investigated. In particular, the effect of different overloads on the fatigue crack growth was simulated using Zencrack code. Preliminary analyses on Compact Tension (CT) specimens proved that the numerical results generated were in agreement with the results provided by an AFGROW code for the same conditions. A case study was carried out on a helicopter component, undergoing repeated overloads, to compare numerical results obtained implementing yield zone models in Zencrack.
\end{abstract}

Keywords fatigue crack propagation; FEM; load spectrum effects; yield zone model.

NOMENCLATURE

$$
\begin{aligned}
a & =\text { crack size } \\
a_{i} & =\text { crack length at step } i \\
A & =\text { coefficient for plane-strain or generalised plane-stress conditions } \\
B & =\text { thickness of the CT specimen } \\
c_{p o} & =\text { length of plastic zone produced by an overload stress } \sigma_{0} \\
C_{o}, n, m & =\text { fatigue material constants } \\
d a / d N & =\text { crack propagation rate } \\
E & =\text { Young's modulus } \\
G & =\text { energy release rate } \\
G_{e q} & =\text { equivalent energy release rate } \\
K_{I}, K_{I I} \text { and } K_{I I I} & =\text { opening, sliding and tearing stress intensity factors (SIFs) } \\
K_{\max , r e q} & =\text { virtual stress intensity factor } \\
K_{\max }^{o l} & =\text { SIF corresponding to the overload } \\
K_{\max , i} & =\text { current maximum SIF of the cycle } i \\
K_{\min , i} & =\text { current minimum SIF of the cycle } i \\
K_{u l} & =\text { underload stress intensity factor } \\
N & =\text { number of fatigue cycles } \\
P & =\text { load } \\
R & =\text { stress ratio } \\
R_{e f f, i} & =\text { effective } R \text { ratio } \\
R_{o l} & =\text { overload ratio } \\
R_{S O} & =\text { shut-off ratio } \\
W & =\text { width of the CT specimen } \\
\alpha & =\text { plastic constraint factor }
\end{aligned}
$$




$$
\begin{aligned}
\Delta a & =\text { crack advance } \\
\Delta K & =\text { SIF range } \\
\theta & =\text { crack propagation direction } \\
v & =\text { Poisson's ratio } \\
\sigma_{R E S} & =\text { residual stress } \\
\sigma_{Y} & =\text { yield stress } \\
\sigma_{0} & =\text { overload stress } \\
\phi & =\text { numerical factor } \\
\omega_{o l} & =\text { plastic radius corresponding to the overload } \\
\omega_{p} & =\text { plastic zone that reaches the boundary of the plastic zone } \omega_{o l}
\end{aligned}
$$

\section{INTRODUCTION}

During an operational lifetime, failures of structural components may occur. These generally yield enormous economic costs and, sometimes, in worst-case scenarios, even a loss of human lives. Frequently, such damage events originate from initial flaws introduced during a manufacturing process, material failures, inappropriate fatigue-strength calculations, a lack of maintenance and others. Beginning from already existing or newly generated flaws, widespread fatigue damage can occur because of service loads, ${ }^{1-4}$ with consequent reduction in component residual strength. ${ }^{5,6}$ Finally, functionality of structures and components can be impaired with the already mentioned consequences. Hence, in case of existing damage events, it is of the uttermost importance to analyse them fundamentally in order to obtain valuable information useful for structural improvements and repairs. Therefore, the knowledge about global and local loadings, relevant material parameters, and initiation and growth of cracks under various general loading situations is essential: it can be obtained with full scale $\mathrm{e}^{2,7,8}$ or reduced scale experimental tests, ${ }^{9}$ but with inherent high levels of costs that not always can be stood, consequently asking for alternative numerical approaches. The development of fatigue crack growth (FCG) processes can be reconstructed by means of fracture mechanics. Therefore, it is possible to improve the strength and fracturesafe design of structures and components. FCG in structural components, subjected to variable amplitude loading, is a complex subject. Analysis of an FCG rate and fatigue life calculation under a spectrum loading is vital in life prediction for engineering structures to guarantee high-reliability levels. ${ }^{10}$ The ability to understand and predict fatigue life remains a key technical factor in maintaining aircraft fleets, which are required to operate safely during their design lives, and, sometimes, beyond.

Load spectra applied to aircrafts during their operational life are complex and highly variable, and experience has shown that traditional fatigue prediction tools do not always perform well in calculating the lives of modern, highly optimised airframes.
This study was performed to address simulation of the so-called retardation effects in fatigue crack propagation, caused by plasticity-induced crack closure that may arise in variable loading condition such as overloads. If a stress intensity factor at the crack tip overcomes the threshold value, the crack propagation is initiated (i.e. stable crack growth), and this can eventually lead to final failure. Once the crack accomplishes regime II and enters into regime III, there is a rapid crack growth, not even leaving a sufficient time for replacement of the component. A possible solution is to implement retardation of the crack propagation before reaching regime II. This delay could allow a sufficient time for a component to get replaced and to minimise operating costs. As well known, application of an overload spike during constant cyclic loading implies a decrease in the crack growth rate because of plasticity-induced crack closure.

The main aim of this research was the assessment of FCG retardation laws into a numerical tool, Zencrack commercial software, ${ }^{11}$ based on an adaptive remeshing method. This software, with the newly enhanced variable amplitude loading capability, enables the selection of the most appropriate models and allows more realistic damage tolerance studies to be performed in threedimensional (3D) components under complex-spectrum loading conditions.

\section{FRACTURE MECHANICS STUDY}

Numerical modelling of a 3D fatigue crack growth under mixed mode conditions ${ }^{12}$ represents a crucial factor in fracture mechanics in order to assess residual life of components. This numerical study is based on finite element (FE) analyses using an adaptive remeshing approach, available in the commercial code Zencrack, for automated 3D remeshing and crack propagation calculations, along with Abaqus, as an FE solver. ${ }^{13}$ Zencrack is a 3D crack analysis tool capable to read an uncracked FE model and to produce a cracked FE model. Stress intensity factors are then calculated automatically from the results of the cracked FE analysis. Furthermore, a crack 
growth can be undertaken by extending the crack surface. An updated FE model is then created and run to simulate the crack growth (Fig. 1).

As an alternative to the previously mentioned fully Finite Element Method (FEM)-based approach, a hybrid FEM-Dual Boundary Element Method (DBEM) ${ }^{14}$ approach could be adopted for such kind of problems.

It is well known that linear-elastic fracture mechanics provides a method for describing a stress state at a crack front. Three modes of local crack behaviour are used to define the opening, sliding and tearing stress intensity factors $K_{I}, K_{I I}$ and $K_{I I I}$, respectively. These can be combined to obtain an equivalent energy release rate term, $G_{e q}$ :

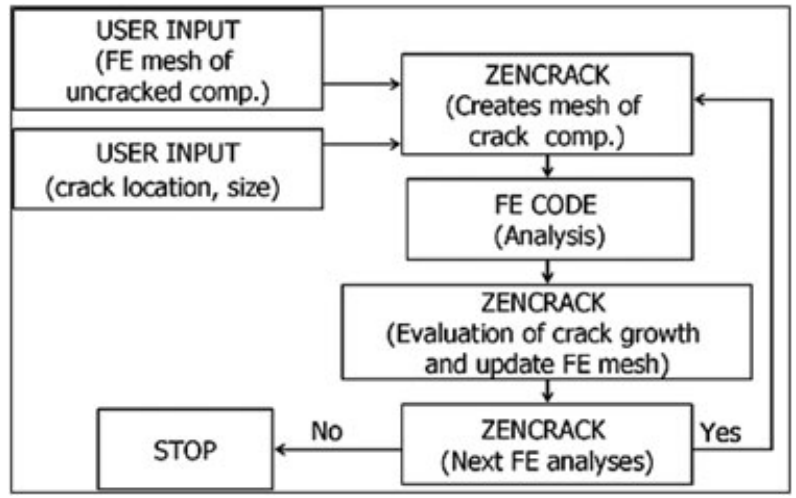

Fig. 1 Flow chart for crack growth prediction analysis. FE, finite element.
$G_{e q}=\frac{1}{\bar{E}}\left(K_{I}^{2}+K_{I I}^{2}\right)+\frac{1}{2 G} K_{I I I}^{2}$,

where $\bar{E}=E /\left(1-v^{2}\right)$ for plane-strain problems. In order to determine new crack front positions, a crack propagation direction must be computed. Although expressions exist to calculate a crack growth angle based upon the stress intensity factors, Zencrack adopts an alternative method based on the maximum energy release rate at a crack front point. The $G$ criterion states that a crack will grow in the direction of the maximum energy release rate. The crack propagation direction, $\theta=\theta_{o}$, is then determined by the following:

$$
\left(\frac{d G}{d \theta}\right)_{\theta=\theta 0}=0 ;\left(\frac{d^{2} G}{d \theta^{2}}\right)_{\theta=\theta_{0}} \leq 0 .
$$

Application of a series of virtual crack extensions ultimately generates a growth angle at the crack front node that, in the general case, may be out of plane.

\section{MODELS FOR PREDICTING CRACK GROWTH UNDER VARIABLE-AMPLITUDE LOADING}

\section{Introduction}

The concepts for predicting the crack growth and the life estimation under variable-amplitude loading are, in gen-

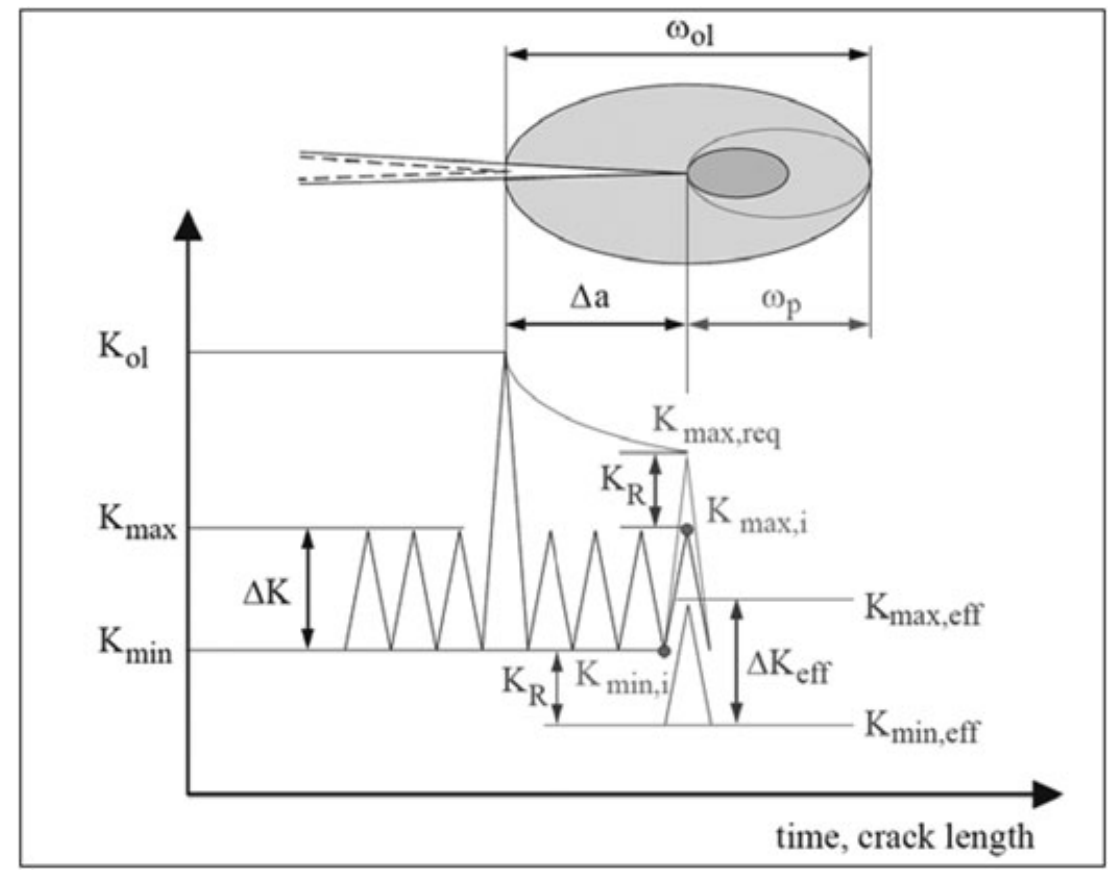

Fig. 2 Determination of effective stress intensity factor in Willenborg model. 


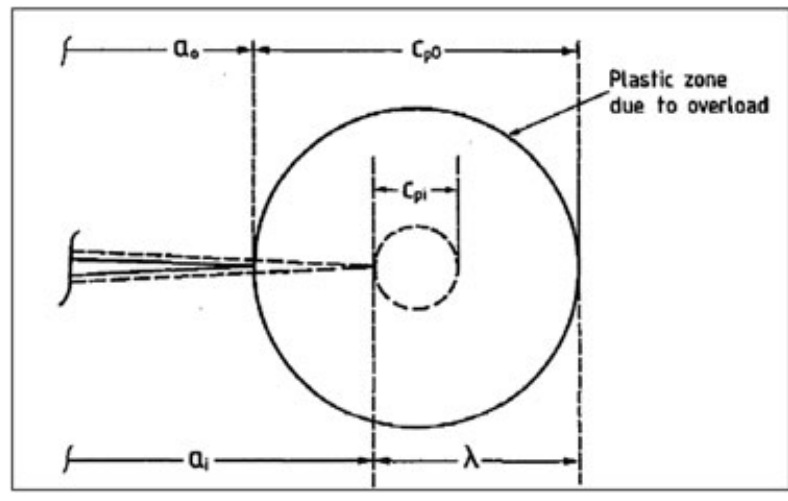

Fig. 3 Crack retardation model proposed by Wheeler.

eral, divided into two different kinds of analyses: global and cycle by cycle.

In the global models, a fatigue crack growth is predicted by accounting for a simultaneous effect of the global loading cycles. The global analyses models are based on a statistical description of the load spectrum. The aim of these models is to calculate only one cyclic stress intensity factor from the whole load spectrum, which can be used in order to characterise the crack growth adequately. For instance, the global analysis concept can predict the FCG, considering an average of the applied loading cycles.

The cycle-by-cycle analysis, used in this study, evaluates each cycle separately, and by accumulation of the separate analyses, the overall analysis is performed. The models, considering the interaction effects, can be divided into three main categories: yield zone models, crack closure models and strip yield models. Only the yield zone models and crack closure models were considered in this study, and a brief description of these models is introduced in this section.
Table 1 Spectrum sequence and applied loads

\begin{tabular}{cll}
\hline & $\begin{array}{c}\text { Load } \\
\text { spectrum 1 }\end{array}$ & $\begin{array}{c}\text { Load } \\
\text { spectrum 2 }\end{array}$ \\
\hline $\begin{array}{c}\text { Spectrum sequence } \\
\text { in cycles }\end{array}$ & 1000 & 100 \\
$R$ ratio & 0.1 & 0.5 \\
$R$ ratio with overload & 0.05 & 0.29 \\
Maximum load $(N)$ & 3600 & 3600 \\
Minimum load $(N)$ & 360 & 1800 \\
Maximum overload $(N)$ & 7200 & 6264 \\
\hline
\end{tabular}

Because the retardation models are less conservative than those not using them at all, care should be paid to the accuracy of the adopted approaches, which must be rigorously validated by experimental tests and crosschecks with different code implementations.

\section{Yield zone models}

In the category of the yield zone schemes, recent models attribute a load interaction effect to plasticity-induced crack closure. Retardation models developed by Willenborg ${ }^{15}$ and Wheeler ${ }^{16}$ are based on the premise that residual stresses in front of the crack tip influence the crack growth rate and are applied by many authors, for example, Pereira et al., ${ }^{17}$ whereas alternative approaches, for example, based on the Unified Approach by Vasudevan, can be seen in Carlone et al., ${ }^{18}$ Citarella et al. ${ }^{19}$ Citarella et al. ${ }^{20}$ Carlone et al. ${ }^{21}$ Citarella et $a l^{22}$ and Citarella et al. ${ }^{23}$.

\section{Willenborg's models}

Basic Willenborg model assumes that the application of an overload determines residual stresses $\sigma_{R E S}$. These

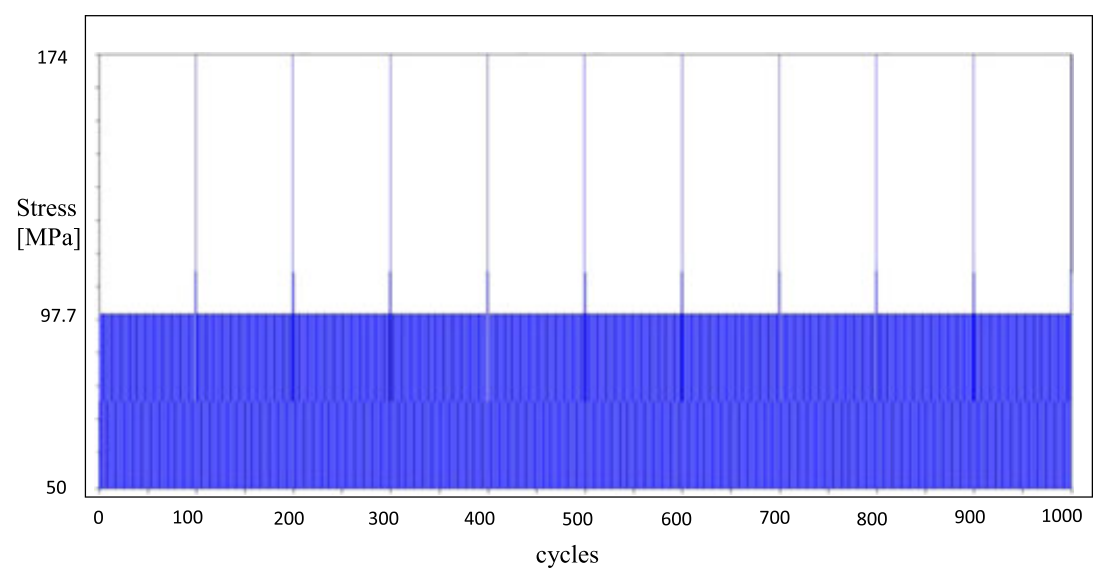

Fig. 4 Load spectrum 2 with overloads repeated every 100 cycles. [Colour figure can be viewed at wileyonlinelibrary.com] 
residual stresses depend on the current loading, the crack growth within the plastic zone and the overload magnitude. To consider the residual stresses, a virtual stress in-

$$
K_{\max , r e q}=K_{\max }^{o l} \sqrt{1-\frac{\Delta a}{\omega_{o l}}}
$$
tensity factor

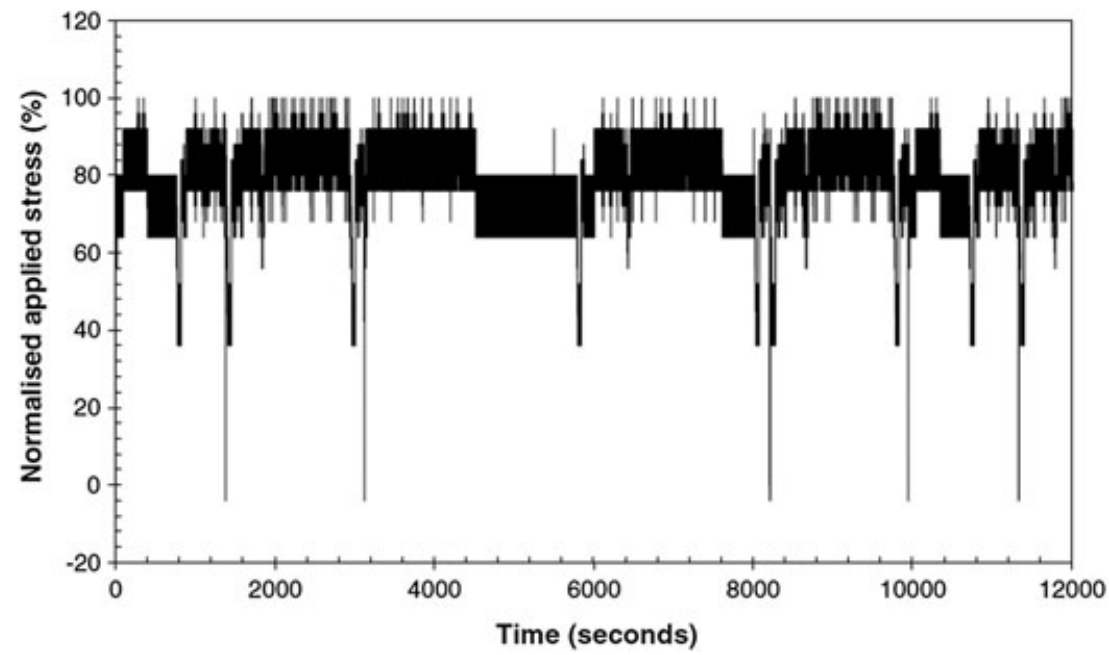

Fig. 5 ASTERIX load spectrum.

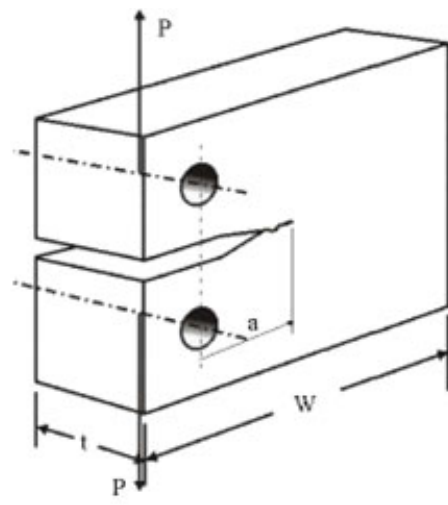

a

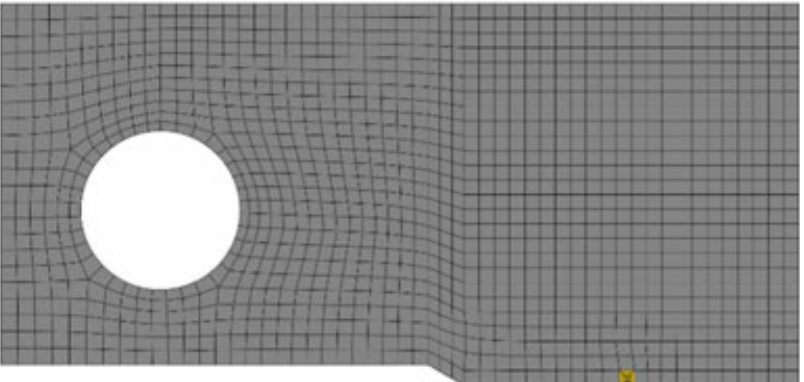

$\mathrm{b}$

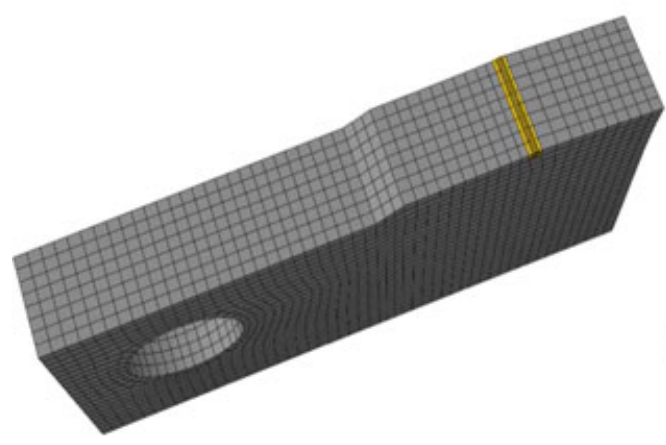

c

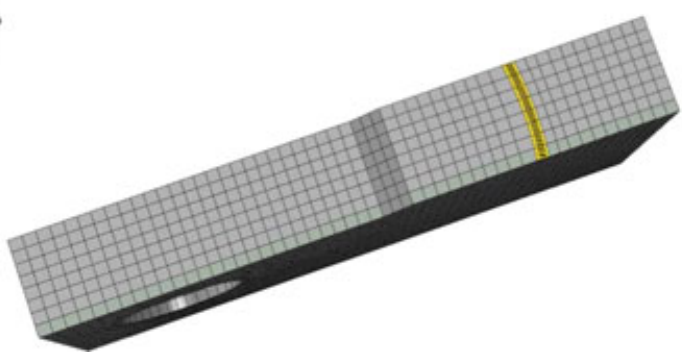

d

Fig. 6 CT specimen used for analysis: (a) isometric sketch; (b) numerical model; and effect of Poisson's ratio (v) on crack shape (yellow area): (c) $v=0.0$ and (d) $v=0.33$. [Colour figure can be viewed at wileyonlinelibrary.com] 
is used. Here, $K_{\max }^{o l}$ is the stress intensity factor corresponding to the overload, $\Delta a$ is the crack advance and $\omega_{o l}$ is the plastic radius corresponding to the overload (Fig. 2). This factor is necessary in order to create a plastic zone of the size

Table 2 Characteristic dimensions of CT specimen

\begin{tabular}{lc}
\hline Width $W(\mathrm{~mm})$ & 40 \\
\hline Thickness $B(\mathrm{~mm})$ & 6.05 \\
Crack length $A(\mathrm{~mm})$ & 15.7 \\
\hline
\end{tabular}

$\omega_{p}=\frac{\pi}{8}\left(\frac{K_{\max , r e q}}{\alpha \sigma_{Y}}\right)^{2}$

that reaches the boundary of the plastic zone $\omega_{o l}$ created by the overload (Fig. 2). The plastic constraints factor $\alpha$ ranges between 1.15 for plane stress and 2.55 for plane strain.

The calculated overload effects are different in the considering plane stress rather than plane-strain effects, because the plastic constraint factor $\alpha$ changes accordingly in Eq. (4). When the specimen's thickness is high

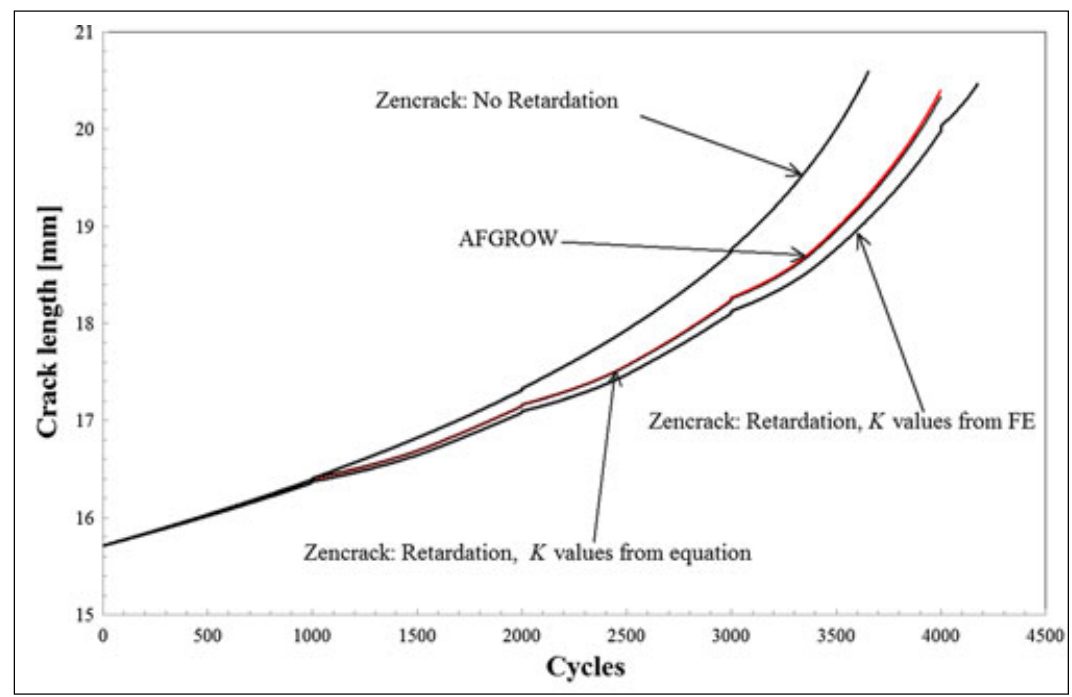

a

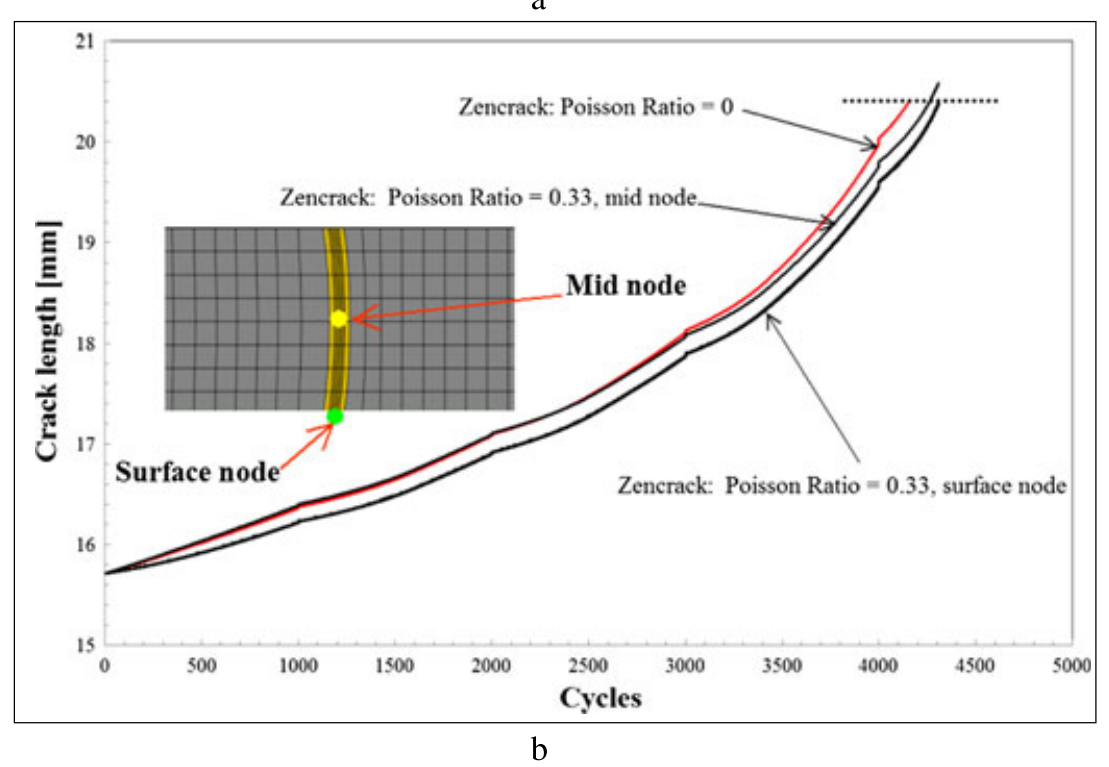

Fig. 7 Results for load spectrum 1: (a) crack growth trend with zero Poisson's ratio and (b) effect of different Poisson's ratios on crack growth. $\mathrm{FE}$, finite element. [Colour figure can be viewed at wileyonlinelibrary.com] 
in comparison with other characteristic sizes (crack length, specimen width and so on), it is possible to assume a single-stress state along the crack front and, in particular, a plane-strain condition because the inherent approximations are relegated to a very limited part of the crack front, in the vicinity of crack breakthrough points. On the contrary, for thin specimens, the planestress hypothesis is well suited.

The difference between the virtual stress intensity factor $K_{\text {max.req }}$ and the current maximum stress intensity factor $K_{\text {max }, i}$ of the following cycle $i$ is defined as residual stress intensity factor $K_{R}$. The retardation effect is a con- sequence of the reduction of the stress intensity factors $K_{m a x, i}$ and $K_{m i n, i}$ in relation to $K_{R}$ and results in the effective cyclic stress intensity factor:

$$
\begin{aligned}
& \Delta K_{\text {eff }, i}=\Delta K_{i} \text { for } K_{\max , e f f, i}>0 \text { and } K_{\min , e f f, i}>0, \\
& \Delta K_{e f f, i}=\cdot K_{\text {max }, e f f, i} \text { for } K_{\min , e f f, i} \leq 0, \\
& \Delta K_{e f f, i}=0 \text { for } K_{\max , e f f, i} \leq 0
\end{aligned}
$$

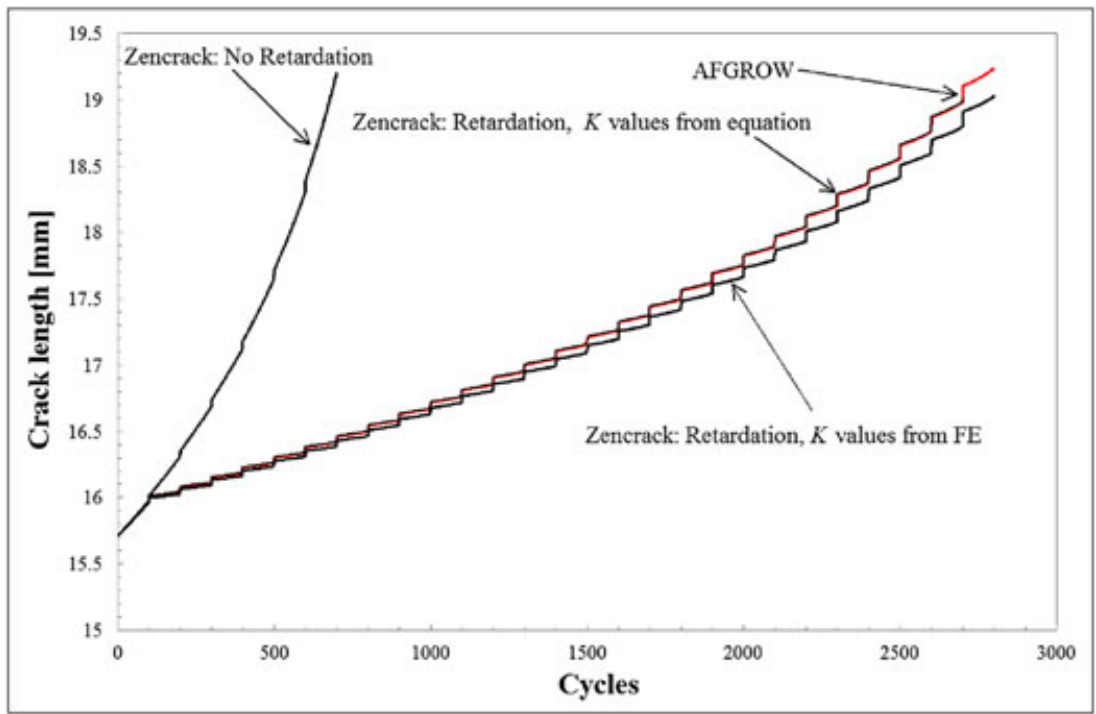

Fig. 8 Crack growth trend with zero Poisson's ratio (load spectrum 2). FE, finite element. [Colour figure can be viewed at wileyonlinelibrary. com]

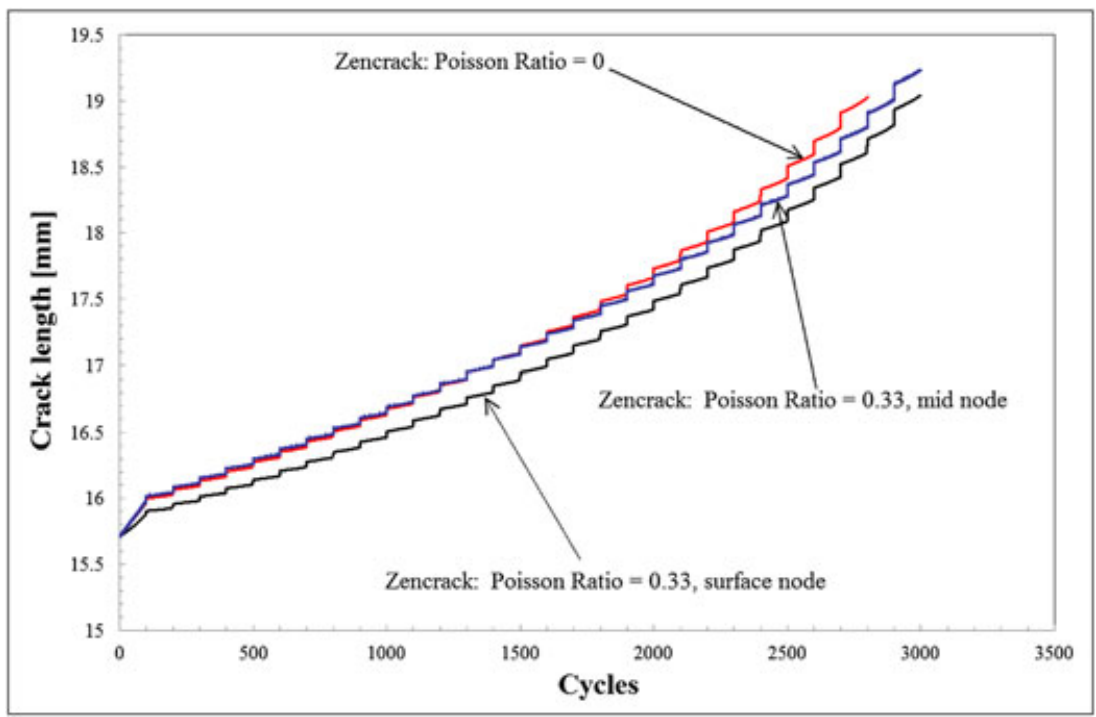

Fig. 9 Load spectrum 2. Effect of different Poisson's ratios on crack growth. [Colour figure can be viewed at wileyonlinelibrary.com] 
and the effective $R$ ratio

$R_{e f f, i}=\frac{K_{\min , e f f, i}}{K_{\max , e f f, i}}$.

The retardation effect is extinguished when the current plastic zone (dark grey in Fig. 2) reaches the boundary of the overload plastic zone (light grey). A disadvantage of this model is that already at an overload ratio $R_{o l}=K_{o l} / K_{\max }=2$ crack arrest is predicted. Due to this fact, this model is improved in the 'generalised
Willenborg model' and implemented in NASGRO. The stress intensity factor $K_{R}$ is multiplied there by a factor:

$$
\varphi=\frac{1-\frac{\Delta K_{t h}}{\Delta K}}{\left(R_{s o}-1\right)}
$$

so that the real shut-off ratio $R_{S O}$ as well as the ratio of the threshold value $\Delta K_{t b}$ and the cyclic stress intensity factor $\Delta K$ are taken into account.

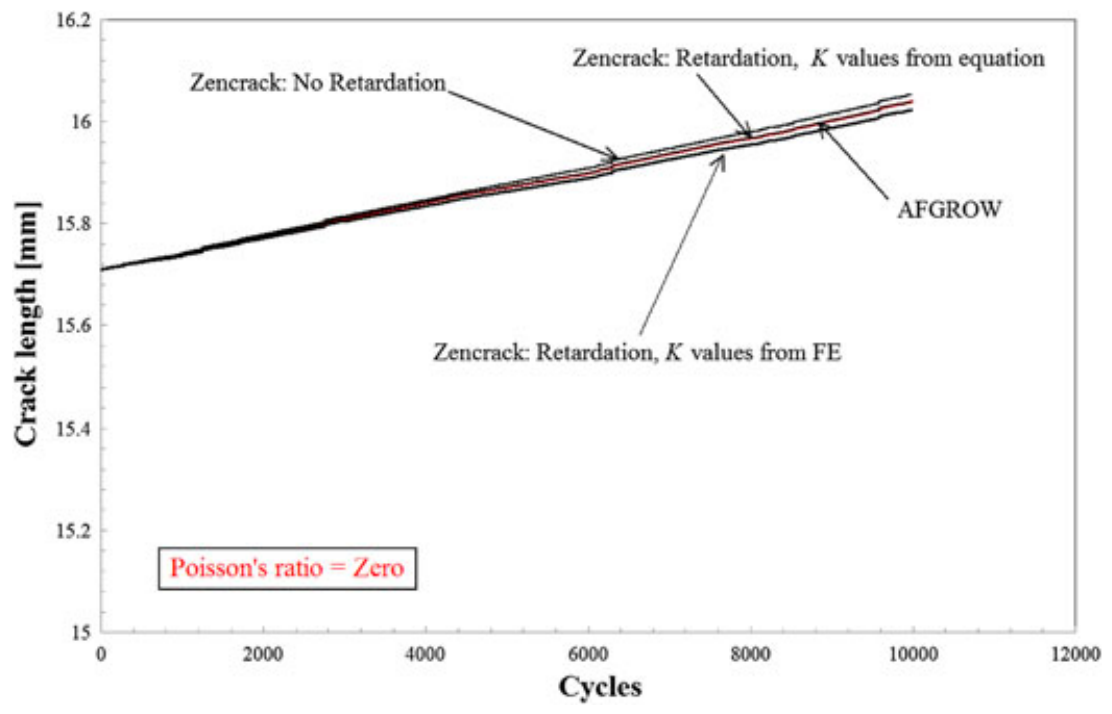

Fig. 10 Crack growth trend with zero Poisson's ratio (ASTERIX load spectrum). FE, finite element. [Colour figure can be viewed at wileyonlinelibrary.com]

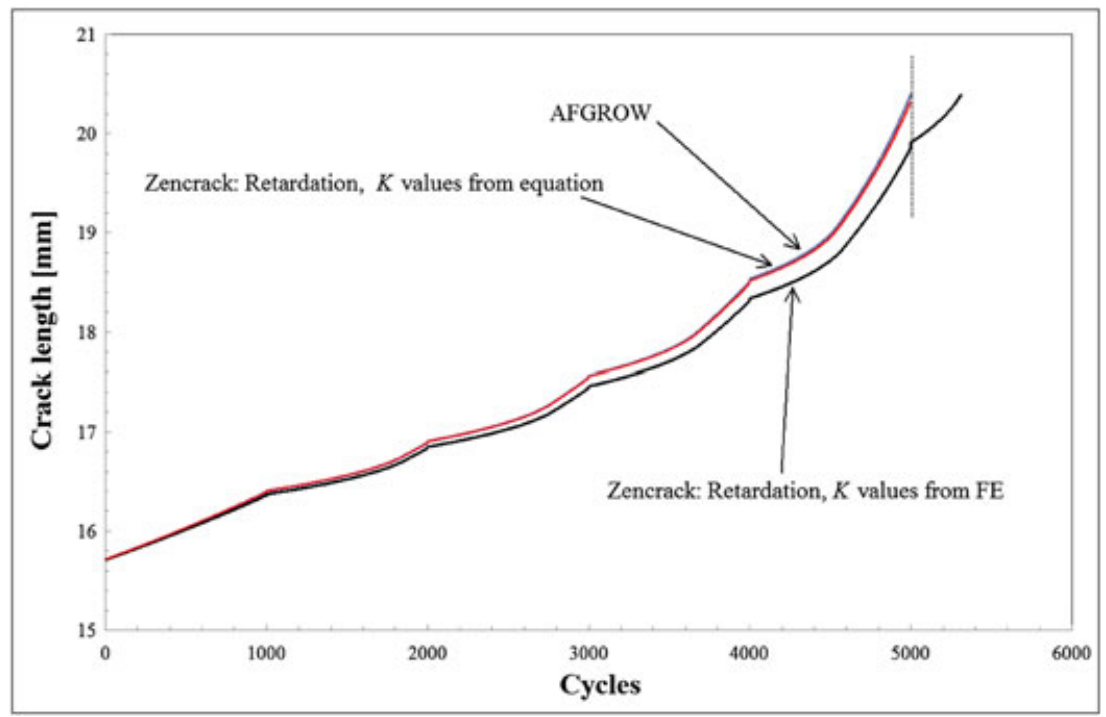

Fig. 11 Crack growth trend with zero Poisson's ratio (load spectrum 1). FE, finite element. [Colour figure can be viewed at wileyonlinelibrary. com] 
In order to consider the reduction of retardation effects due to underloads, the modified Willenborg model (generalised Willenborg) was developed by Brussat and implemented in the AFGROW and NASGRO codes. Both methods are also implemented in Zencrack. The factor $\phi$ is now given by the following:

$$
\begin{aligned}
\phi & =2.523 \phi_{0} /\left[1.0+3.5\left(0.25-R_{u l}\right)^{0.6}\right] \text { if } R_{u l}=\frac{K_{u l}}{K_{o l}} \\
& <0.25 \\
\phi & =1.0 \text { if } R_{u l}=\frac{K_{u l}}{K_{o l}}>0.25,
\end{aligned}
$$

whereby $\phi_{0}$ is the value of $\phi$ for $R_{u l}=0$ and $K_{u l}$ is the underload stress intensity factor.

\section{Wheeler's model}

A model based on crack retardation proposed by Wheeler assumes that, after a peak load, there is a load interaction effect when the crack tip plastic zones for the subsequent loads are smaller than that because of the peak load. Consider that at a crack length $a_{0}$, an overload stress $\sigma_{0}$ creates a crack tip plastic zone of length $c_{p o}$ (Fig. 3), which is given by the following:

$c_{p o}=\frac{1}{A} \frac{\sigma_{0}^{2} a_{0}}{\sigma_{Y}^{2}}$
Table 3 Comparison of life (in cycles) before application of a single overload

\begin{tabular}{cccc}
\hline \multicolumn{4}{c}{ Values measured at crack extension of $16 \mathrm{~mm}, v=0$, load } \\
spectrum 1 \\
\hline Wheeler & AFGROWZencrack \\
coefficient & \multicolumn{4}{c}{$\begin{array}{c}\text { K from finite } \\
\text { element }\end{array}$} & $K$ from \\
& 454 & 478 & 454 \\
1 & 454 & 478 & 454 \\
1.5 & 454 & 478 & 454 \\
2 & 454 & & \\
\hline
\end{tabular}

with $A=1$ or 3 for plane-strain or generalised planestress conditions, respectively. When the crack propagated to a length $a_{i}$, a stress $\sigma_{i}$ produces a plastic zone of length $c_{p i}$ given by the following:

$\phi=\left(c_{p i} / \lambda\right)^{\mathrm{m}}$ for $a_{i}+c_{p i}<a_{0}+c_{p o}$,

where $\lambda=a_{0}+c_{p o}-a_{i}$ and $m$ are empirical parameters.

Then the crack growth increment for $a_{i}+c_{p i}<a_{0}+c_{p o}$ is given by the following:

$(d a / d N)_{R}=\phi(d a / d N)$

where $d a / d N$ is the constant-amplitude crack propagation rate corresponding to the stress intensity factor range $\Delta K_{i}$ of the load cycle $i$.

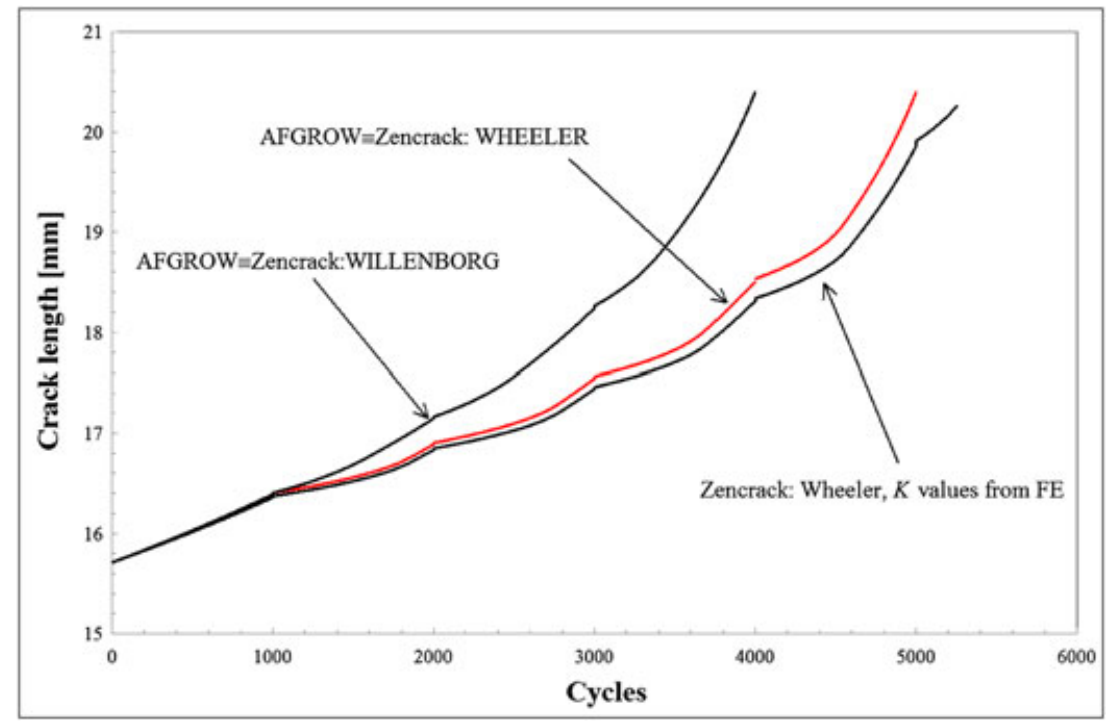

Fig. 12 Crack growth trends with Willenborg and Wheeler models (load spectrum 1). FE, finite element. [Colour figure can be viewed at wileyonlinelibrary.com] 
When $a_{i}+c_{p i}>a_{0}+c_{p o}$, the crack has crossed the plastic region, and the retardation factor is assumed to be $\phi=1$.

Table 4 Comparison of life (in cycles) after application of the first overload

Values measured at crack extension of $17 \mathrm{~mm}, v=0$, load spectrum 1

\begin{tabular}{cccc}
\hline $\begin{array}{c}\text { Wheeler } \\
\text { coefficient }\end{array}$ & $\begin{array}{c}\text { AFGROWZencrack } \\
K \text { from finite } \\
\text { element }\end{array}$ & $\begin{array}{c}K \text { from } \\
\text { equation }\end{array}$ \\
1 & 2278 & 2436 & 2286 \\
1.5 & 3482 & 3721 & 3491 \\
2 & 5537 & 5962 & 5538 \\
\hline
\end{tabular}

Table 5 Comparison of life (in cycles) at extended crack growth after repeated overloads

Values measured at crack extension of $20 \mathrm{~mm}, v=0$, load spectrum 1

\begin{tabular}{cccc}
\hline $\begin{array}{c}\text { Wheeler } \\
\text { coefficient }\end{array}$ & AFGROWZencrack & $\begin{array}{c}K \text { from finite } \\
\text { element }\end{array}$ & $\begin{array}{c}K \text { from } \\
\text { equation }\end{array}$ \\
1 & 4892 & 5081 & 4911 \\
1.5 & 7983 & 8603 & 7999 \\
2 & 15666 & 16144 & 15670 \\
\hline
\end{tabular}

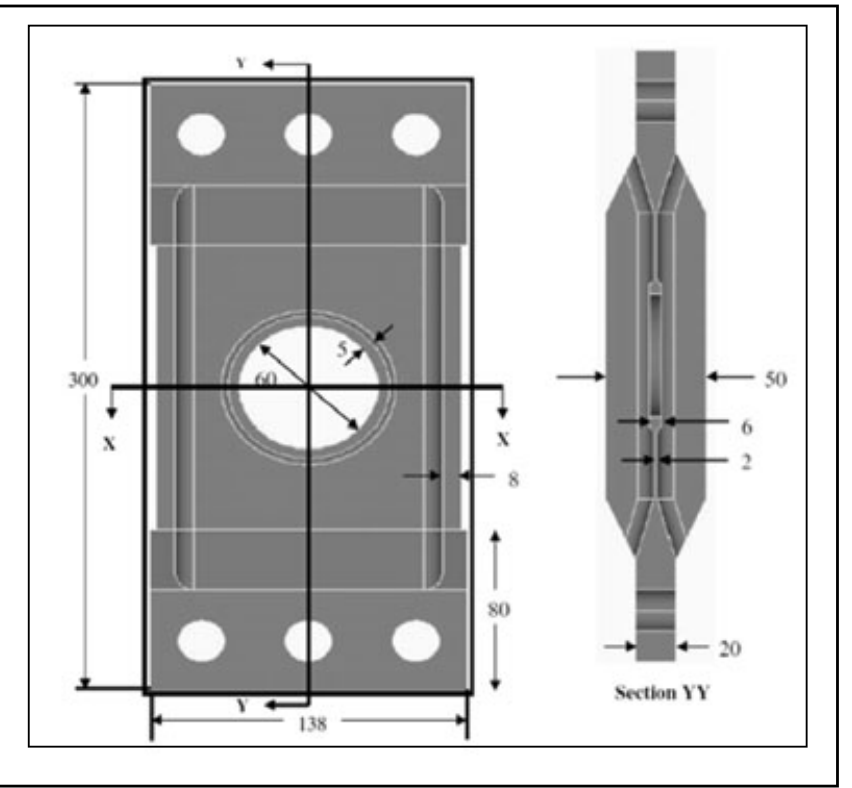

\section{CRACK GROWTH LAW AND FATIGUE MATERIAL PROPERTIES}

In the present work, the Walker equation was used to simulate a fatigue crack growth:

$\frac{d a}{d N}=C_{o}\left[\Delta K_{R}(1-R)^{(\mathrm{n}-1)}\right]^{\mathrm{m}}$,

where $a$ is the crack size and $N$ is the number of fatigue cycles; $\mathrm{C}_{o}, n$ and $m$ are the material constants (subscript 0 refers to values at $R=0) ; \Delta K=K_{\max }-K_{\min }$ is the stress intensity factor range and $R$ is the stress ratio. $\mathrm{Pa}$ rameters for AL 2024-T3 used in this work for the Walker equation are $C_{o}=5.85178 \mathrm{E}-14, m=3.59$ and $n=0.68$ (as available from AFGROW database); these values were obtained with the units of $\mathrm{MPa} \sqrt{\mathrm{m}}$ for $\Delta K$ and $\mathrm{mm}$ per cycle for $d a / d N$. The crack geometry investigated in this research was a through crack for the CT specimen.

\section{LOAD SPECTRA}

The CT specimen was subjected to two different load spectra (LSP 1 and LSP 2), based on blocks composed by 1000 or 100 cycles, respectively, each baseline sequence with different $R$ ratios. An example of an overload
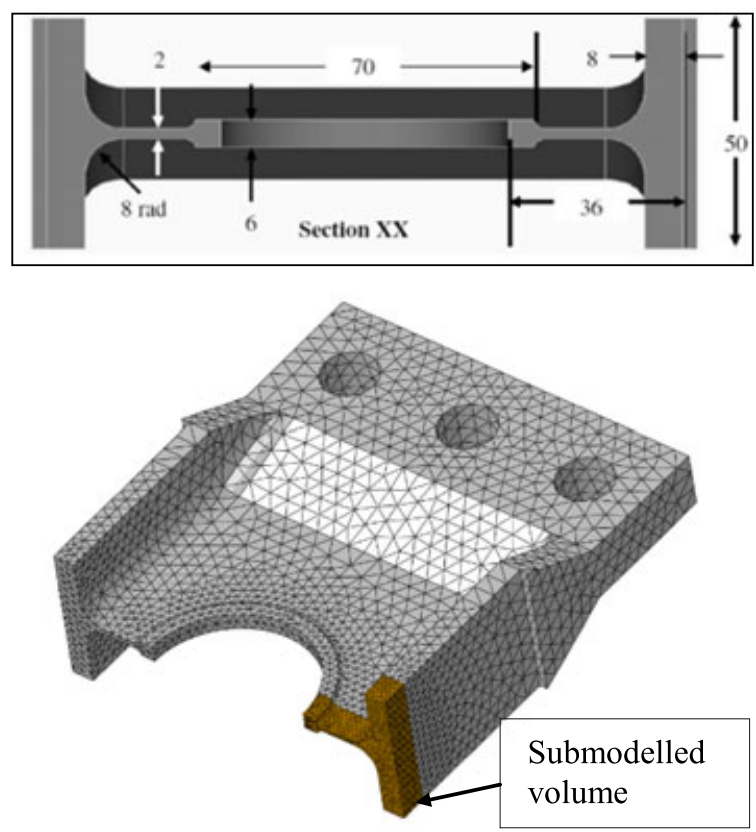

Fig. 13 Helicopter lift frame component: geometric dimensions, overall FEM mesh and submodelled volume. [Colour figure can be viewed at wileyonlinelibrary.com] 
sequence is presented in Fig. 4, in which the overload was applied every 100 cycles, at the last cycle of the elementary-iterated block. The loading sequence was repeated until the critical stress intensity factor was reached in computational analyses or no further crack extension was achievable. Details of the spectrum loadings are summarised in Table 1.

Tests with realistic load sequences are often required in order to demonstrate the in-service integrity for the given materials and structures. For this purpose, standardised load-time histories have been developed for 30 years, because it was recognised that this use provided a series of advantages - both for studies of a more generic nature and practical applications. ${ }^{24}$
One of these standardised load-time histories is named ASTERIX (Fig. 5) and was introduced here with the purpose to test FE results in more realistic loadspectrum conditions.

\section{FINITE ELEMENT MODELLING}

\section{CT specimen}

Results of the retardation models implemented in Zencrack were also compared with those of other computational tools for fatigue crack growth. In particular, code AFGROW, broadly used in the aerospace industry

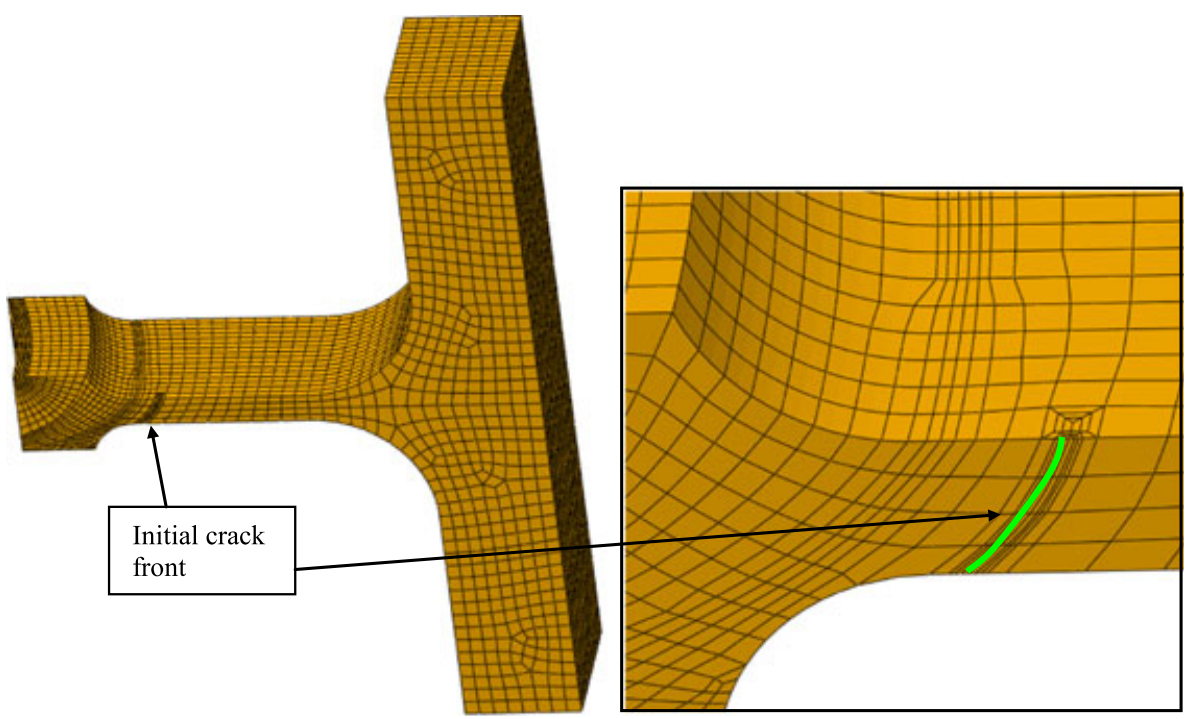

a

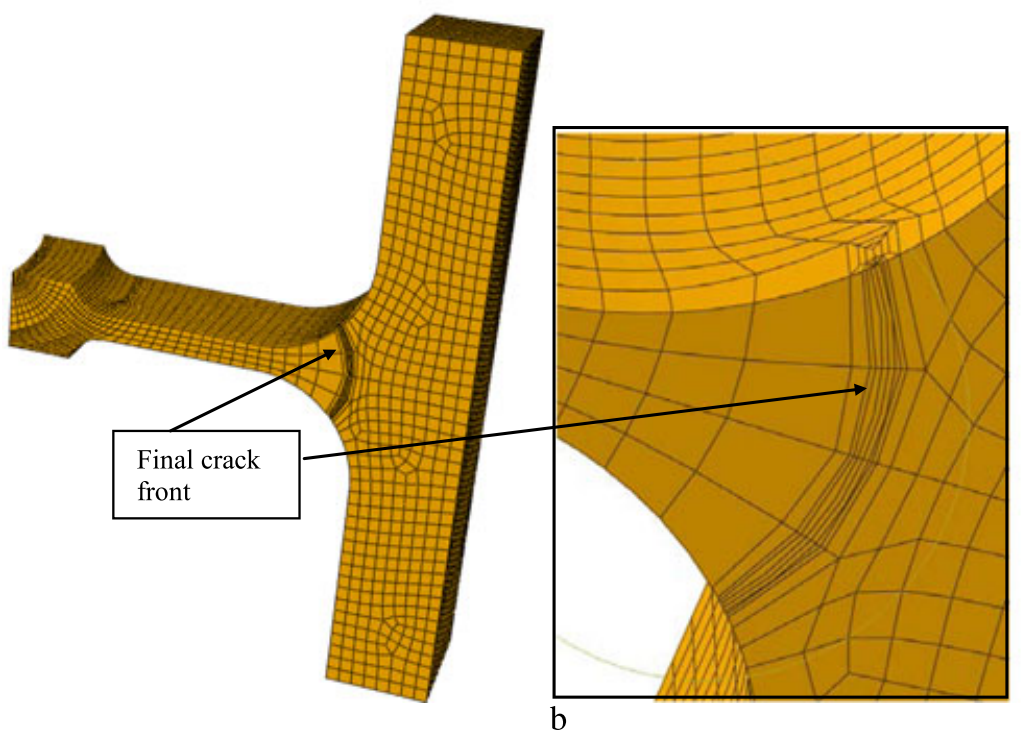

Fig. 14 FEM-cracked submodel with close up of initial (a) and final (b) modelled cracks. [Colour figure can be viewed at wileyonlinelibrary. com] 
for damage tolerance analyses, was used to compare numerical results for the CT specimen investigated. A 3D numerical model used in this study is presented in Fig. 6. Because of the symmetry of the CT specimen shown in Fig. 6a, only one half of the specimen was analysed. The effect of the Poisson's ratio on a crack shape can be seen in Fig. 6c-d.

In order to compare the FE results obtained with Zencrack and the analytical-based solution of AFGROW, two numerical approaches were considered. The first approach considered was the real Poisson's ratio (equal to 0.33) of AL 2024-T3 (Fig. 6d), while in the second model, the Poisson's ratio was set equal to 0 to simulate a two-dimensional behaviour of crack propagation (Fig. $6 c)$. The same zero value of the Poisson's ratio was used in the analyses performed with AFGROW, which cannot simulate the effects of varying plane-stress/plane-strain conditions along the crack front. In fact, calculations of the crack growth in AFGROW cannot take into account the realistic stress fields of $\mathrm{FE}$ analyses. For this reason, it was essential to establish similar 'physical' conditions to provide comparability of the data from the two computational solutions. As a matter of fact, the 3D FEM analysis was reduced to a two-dimensional one, as that performed by AFGROW code, by setting to 0 the Poisson's ratio.

Furthermore, to minimise any possible mismatch in the results of the two computational methods, a subroutine in Zencrack was implemented to match the evaluation of the stress intensity factors exactly with the same formula adopted in AFGROW (rather than using values calculated by the $\mathrm{FE}$ analysis). Equations used to evaluate the stress intensity factors with the AFGROW method are as follows:

\section{Finite element analyses}

The retardation models available in Zencrack are based on the standard schemes available in the literature and in AFGROW software. The use of these retardation models in Zencrack accounts for a beneficial effect of overloads and gets a better estimate of residual life of the component.

A full set of analyses was carried out to examine the effect of the retardation models on crack propagation. The following types of computational analyses were implemented:

1 Crack propagation without the retardation model (notation in figures with results: 'Zencrack: no retardation');

2 Crack propagation with retardation model and stress intensity factors evaluated via $\mathrm{FE}$ analysis ('Zencrack: retardation, $K$ values from FE');

3 Crack propagation with the retardation model and stress intensity factors evaluated via Eq. (14) ['Zencrack: retardation, $K$ values from Eq. (14)'];

4 AFGROW code solution (AFGROW curve in the figures); and

5 The AFGROW analyses were performed only for the Poisson's ratio equal to 0 , while two levels -0.0 and 0.33 - were considered in the FE study.

The elements used in the numerical analyses were fully integrated 20-node hexahedral elements. A mesh generated in the cracked model consisted of quarterpoint crack tip elements along the crack front in order to enforce correctly the theoretical $r^{-1 / 2}$ singularity in the FE simulations of crack propagation.

It should be noted that the AFGROW calculations used the optimum re-evaluation of $K$ at every cycle,

$f\left(\frac{A}{W}\right)=\left[{ }^{\left(2+\frac{A}{W}\right)} / /_{1.0-}\left(\frac{A}{W}\right)^{1.5}\right] *\left[0.886+4.64\left(\frac{A}{W}\right)-13.2\left(\frac{A}{W}\right)^{2}+14.72\left(\frac{A}{W}\right)^{3}-5.6\left(\frac{A}{W}\right)^{4}\right]$,

$K=\left[P * f\left(\frac{A}{W}\right)\right] /(B * \sqrt{W})$,

where $A$ is the crack length, $P$ is the applied load, $B$ is the thickness and $W$ is the width of the CT specimen.

The total number of elements used in the analysis was 10 248; quadratic interpolation (C3D20 element types) was used for the FE analyses. Dimensions of the CT specimen are summarised in Table 2. whereas Zencrack methodology, although using the same basic $K$ equation, has only finite evaluations of $K$ with appropriate handling of $K$ variations during the integration process as the crack extends. The two sets of results match perfectly.

It is worthwhile to consider that there is no direct impact of mesh quality in relation to application of the overload effects, because the latter are evaluated resorting to a phenomenological approach (which needs a specific calibration by experimental tests based on similar spectra). 
As a matter of fact, if a mesh is sufficiently refined for a standard constant amplitude analysis, it turns out to be automatically acceptable also when allowing for loadspectrum effects by the aforementioned retardation models (Willenborg ...). On the contrary, when using a physically based approach, like that proposed by Vasudevan, it is of the uttermost importance to have a very refined mesh close to the crack front in order to model properly the distribution of residual stresses originated by the overload, and superimposed on the stress state generated by remote loading conditions.

\section{FATIGUE CRACK GROWTH NUMERICAL SIMU- LATIONS AND RESULTS COMPARISON}

\section{Willenborg generalised model}

The Willenborg generalised model was first adopted to analyse the sequence effects produced by the two considered load spectra.

\section{Load spectrum 1}

Comparison of data for load spectrum 1 (Table 1) is presented in Fig. 7: the lack of $\mathrm{c} 1$ continuity is a consequence of overload introduction and a subsequent impact on the crack growth rate. The effect of the retardation is quite evident in Fig. 7a after the first overload at 1000 cycles; it is repeated regularly every 1000 cycles. The introduction of the retardation strategy leads to an increase of nearly $12.5 \%$ in the final life estimation calculated with Zencrack with the stress intensity factors evaluated using the FE solver. The solution given by the code AFGROW and Zencrack, with stress intensity factors evaluated 'analytically' through Eq. (14), results in a slightly less beneficial effect, that is, $8.6 \%$. However, it is interesting to note that the solution achieved using Zencrack with calculation of the stress intensity factors based on the AFGROW methodology perfectly matches the AFGROW results.

The effect of stress triaxiality due to the real Poisson's ratio $(v=0.33)$ is evident in Fig. $7 \mathrm{~b}$. In this case, a realistic stress field was established in the numerical model.

\section{Load spectrum 2}

Load spectrum 2 (Table 1) was introduced with the purpose to produce FE results (Zencrack) for more realistic load-spectrum conditions and, in particular, with a radical increase in the number of repeated overloads and with a reduced $R$ ratio. From the obtained results (Fig. 8), it is possible to first evaluate the effect of the increase in the number of repeated overloads. The overall increase in terms of a number of cycles compared with that in the non-retarded simulations was nearly $285 \%$. More importantly, Fig. 8 demonstrates that the FE results using Zencrack still provided perfect match with the AFGROW results, and in particular, the curve of the Zencrack values obtained by means of Eq. (14) still overlays the AFGROW curve.

The effect of the Poisson's ratio on the crack growth for load spectrum 2 is presented in Fig. 9. There, the Poisson's ratio results are representative of the more realistic crack front shape shown in Fig. 6d.

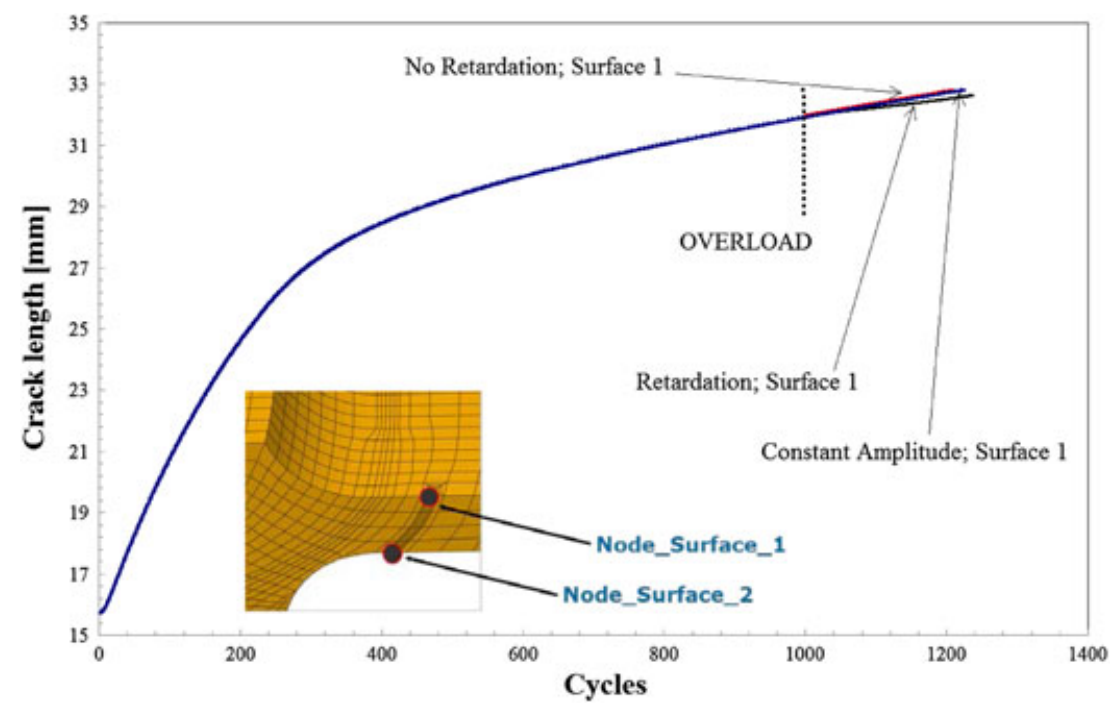

Fig. 15 Evolution of crack length on surface 1 with cycles, with or without retardation effects when applying just one overload and load spectrum 1. [Colour figure can be viewed at wileyonlinelibrary.com] 


\section{ASTERIX load spectrum}

The effect of ASTERIX load spectrum in terms of number of cycles can be evaluated from Fig. 10 and compared with the non-retarded simulations. Fig. 10 shows again that the FE results using Zencrack are still in a perfect match with the AFGROW results and, in particular, the curve of the Zencrack values obtained by means of Eq. (14) coincides with the AFGROW curve. More interestingly, it is possible to see how complex spectra can result only in negligible changes in life estimation (Fig. 10).

\section{Wheeler model}

A comparison of data for load spectrum 1 calculated with the Wheeler model is presented in Fig. 11: here, the effect of the retardation is quite evident after the first overload at 1000 cycles, and it is repeated regularly every 1000 cycles. The solution given by the code AFGROW

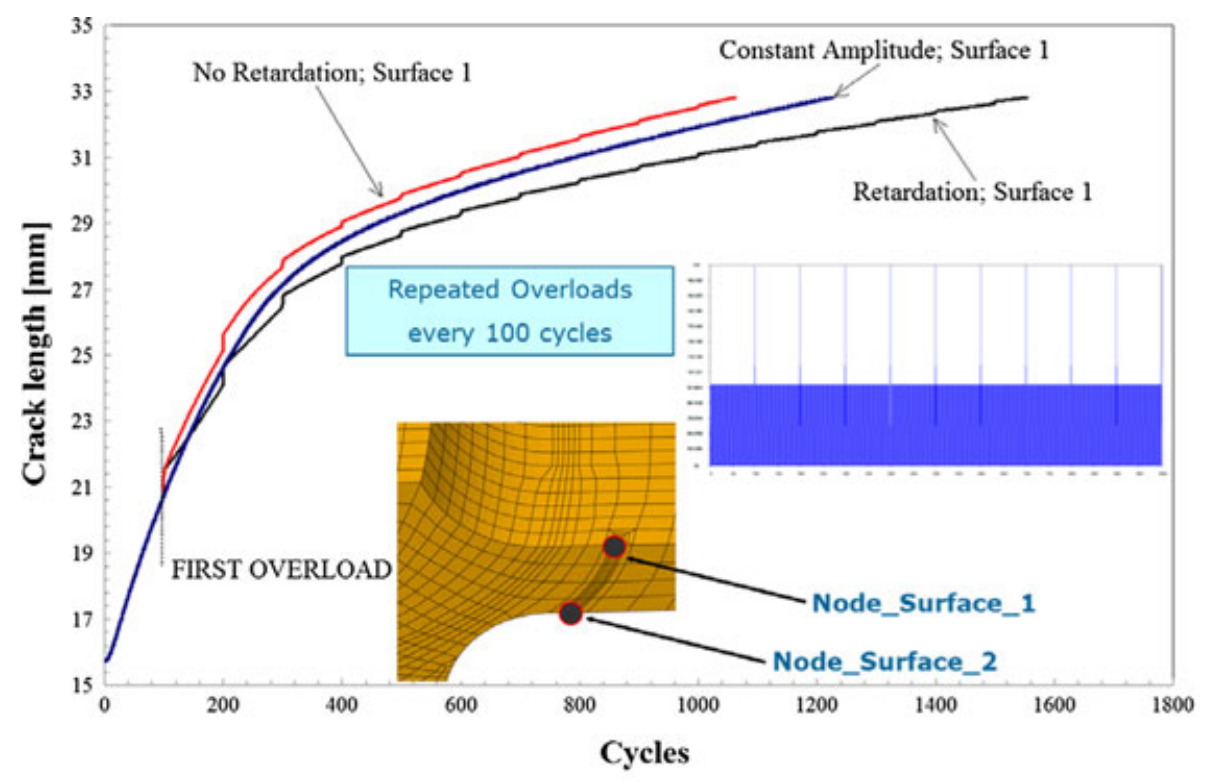

(a)

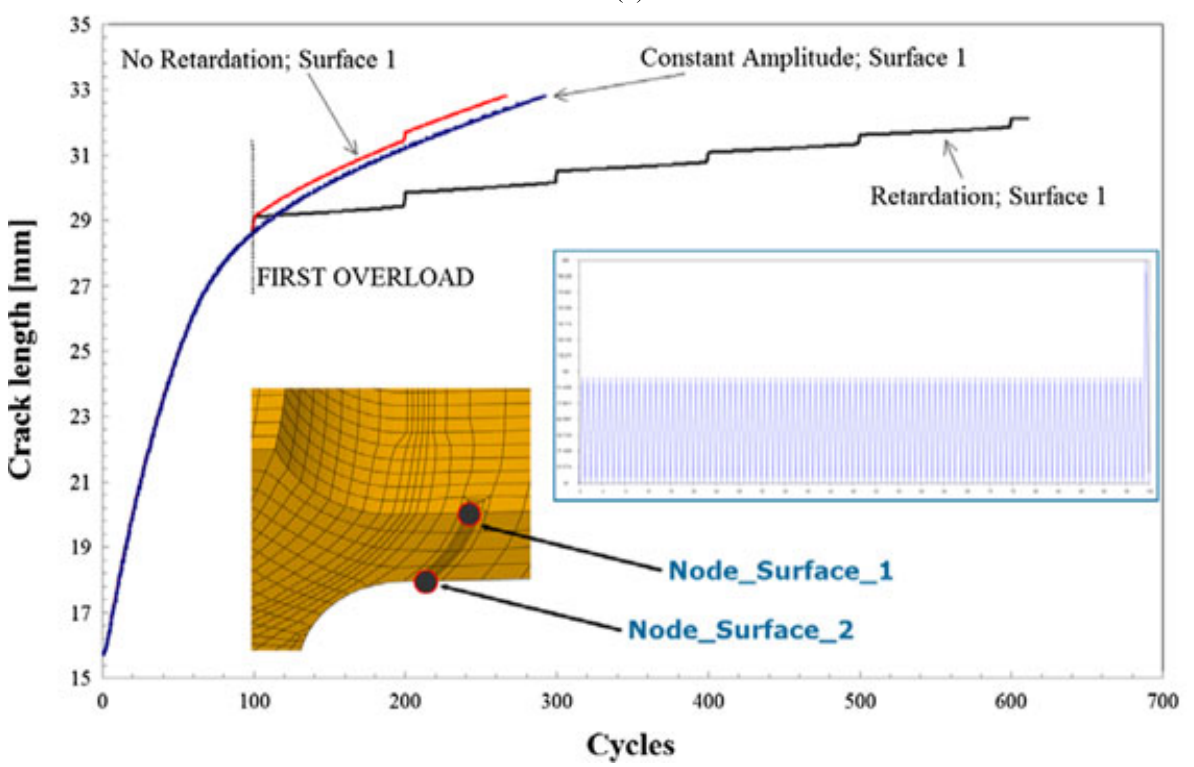

(b)

Fig. 16 Evolution of crack length on surface 1 with cycles with or without retardation effects by load spectrum 2 with repeated overloads for various cases of the first overload application: (a) crack length of $21 \mathrm{~mm}$ and (b) crack length of $29 \mathrm{~mm}$. [Colour figure can be viewed at wileyonlinelibrary.com] 
and Zencrack, with stress intensity factors evaluated 'analytically' through Eq. (14), results in a slightly less beneficial effect. However, it is interesting to note that the solution achieved using Zencrack with calculation of the stress intensity factors based on the AFGROW methodology perfectly matches with the AFGROW results.

A comparison between the Willenborg and Wheeler models is presented in Fig. 12.

A comparison of the life before (Table 3) and after (Table 4) application of a single overload and after repeated overloads (Table 5) is also presented.

\section{Case study: generalised Willenborg applied to heli- copter frame \\ Introduction}

In order to demonstrate the capability of the method, a case study was investigated. This study was carried out on a helicopter component (Fig. 13) undergoing repeated overloads. These investigations aim to understand the overall effects of real-life complex loading spectra that typically occur during the operative life of helicopters (and, more in general, by aircraft).

The initial cracked model is shown in Fig. 14a; the numerical model was obtained with an adaptive remeshing technique applied on the initial uncracked mesh (Fig. 13). The crack propagation in the frame is depicted in Fig. 14b.

In particular, in order to model accurately the details of crack fronts, the 'standard crack blocks' approach was adopted in this study, which reduces to a single element on their back faces and merges with the rest of the mesh via shared nodal numbers.

\section{Load spectra 1 and 2}

The calculated negligible retardation effects caused by a single overload, applied after 1000 baseline cycles (load

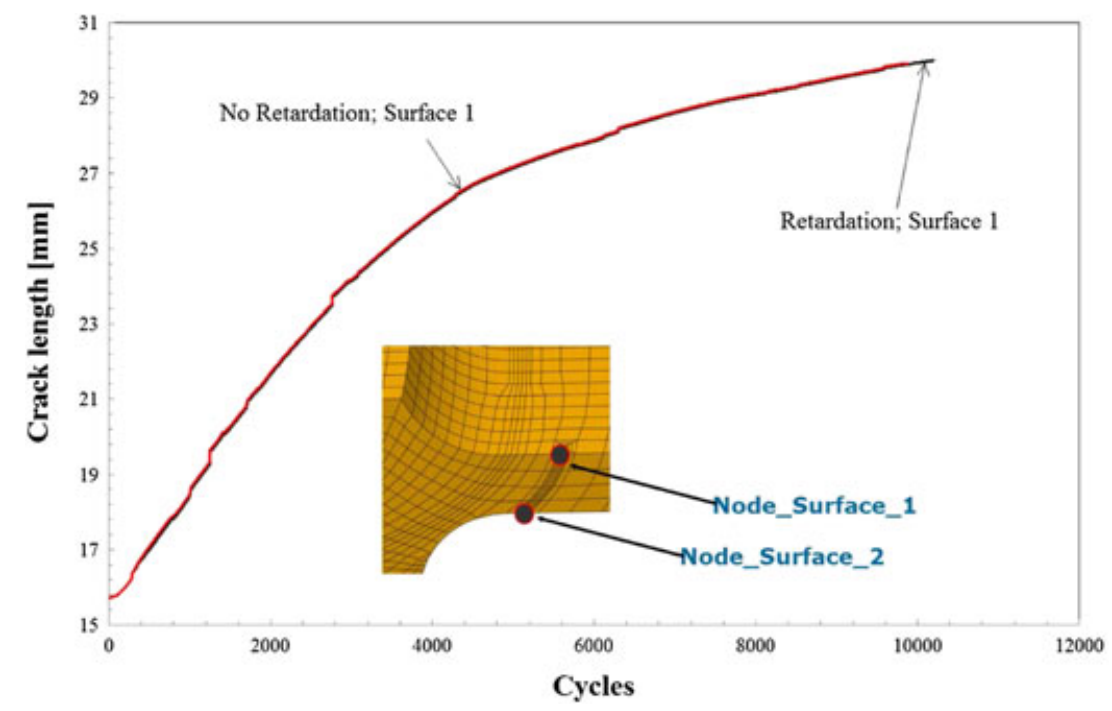

Fig. 17 Evolution of crack length (measured at breakthrough point on surface 1) with cycles with and without allowance for sequence effects induced by ASTERIX load spectrum. [Colour figure can be viewed at wileyonlinelibrary.com]

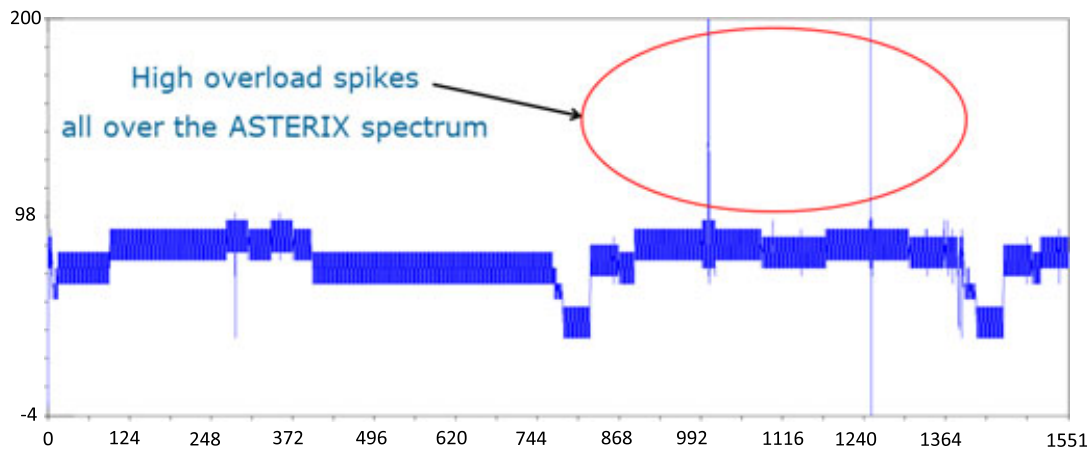

Fig. 18 Modified ASTERIX load spectrum. [Colour figure can be viewed at wileyonlinelibrary.com] 


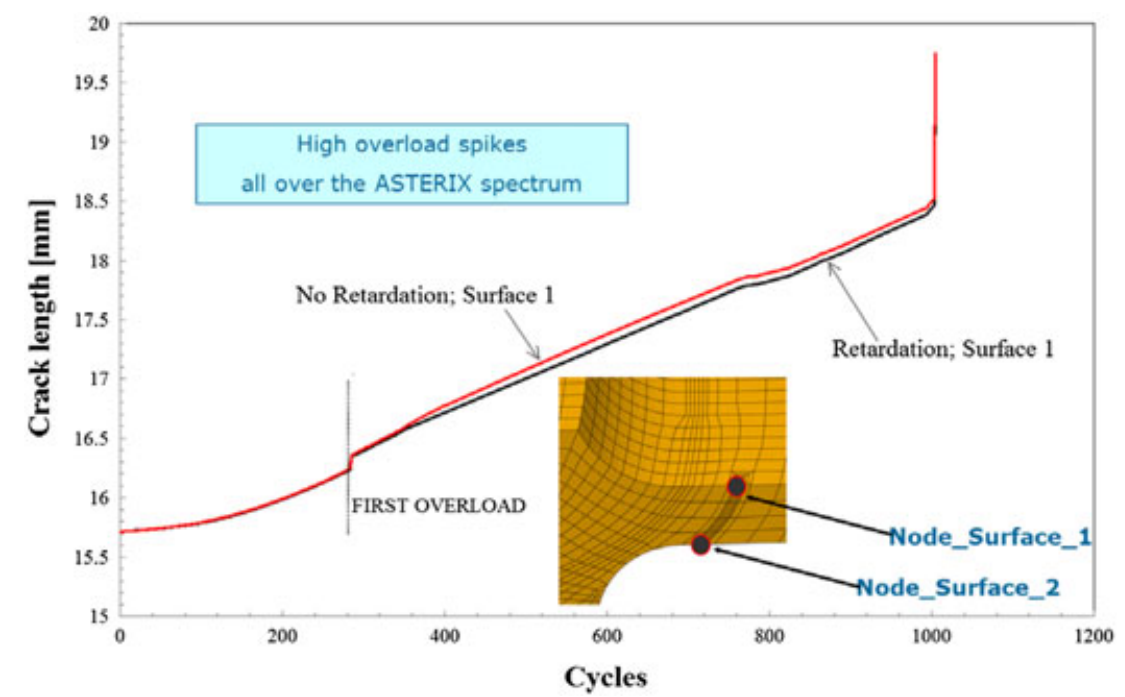

Fig. 19 Evolution of crack length (measured at breakthrough point on surface 1) with cycles with and without allowance for sequence effects induced by modified ASTERIX load spectrum. [Colour figure can be viewed at wileyonlinelibrary.com]

spectrum 1), are shown in Fig. 15: the plotted crack length is related to the reference node placed on surface 1 .

Unlike load spectrum 1, the influence of repeated overloads, each applied after 100 baseline cycles (load spectrum 2), resulted in a significant retardation of crack propagation in the modelled component (Fig. 16a-b).

Different retardation results shown in Fig. 16a-b are related to various crack lengths when the first overload was applied.

Although the amount of applied overload was the same, the stress intensity factors were different and, in particular, higher for longer crack lengths (Fig. 16b). Consequently, larger plastic zones were formed in the proximity of the crack tips. These extended plastic regions were, therefore, responsible for more pronounced retardation under load spectrum 2 .

\section{ASTERIX load spectrum}

The application of complex spectra like ASTERIX (Fig. 5) produced some interesting numerical results. In fact, only meaningless and totally negligible changes in life estimation were detected, as shown in Fig. 17.

Consequently, in order to introduce appreciable retardation effects, the ASTERIX spectrum was modified by adding high or moderate overload spikes (Fig. 18), with the impact illustrated in Fig. 19.

\section{CONCLUSIONS}

In this research, fatigue crack growth behaviour of aeronautical aluminium alloy 2024-T351 was studied. Effects of various loading conditions such as the stress ratio and various amplitude loadings were investigated. In particular, the effect of different overloads on the fatigue crack growth rate was simulated using the Zencrack code. Preliminary analyses on the CT specimen proved that the numerical results generated using Zencrack were in agreement with the results provided by the AFGROW code for the same conditions. A case study was carried on a helicopter component under repeated overloads to compare numerical results obtained implementing yield zone models in Zencrack.

In conclusion, the proposed procedure exhibited the capability to perform FE analysis under nonproportional loading conditions for two-dimensional and 3D formulations and, in particular, with reference to a realistic test case, where the effects of overload and complex spectrum loadings were assessed.

\section{REFERENCES}

1 Citarella, R. (2009) Non-linear MSD crack growth by DBEM for a riveted aeronautic reinforcement. Advances in Engineering Software, 40, 253-259.

2 Armentani, E., Citarella, R. and Sepe, R. (2011) FML full scale aeronautic panel under multiaxial fatigue: experimental test and DBEM simulation. Engineering Fracture Mechanics, 78, 1717-1728.

3 Citarella, R. (2011) MSD crack propagation on a repaired aeronautic panel by DBEM. Advances in Engineering Software, 42, 887-901.

4 Citarella, R. (2016) Multiple crack propagation by DBEM in a riveted butt-joint: a simplified two-dimensional approach. Frattura ed Integrità Strutturale, 36, 160-167. 
5 Citarella, R. (2015) Residual strength evaluation by DBEM for a cracked lap joint. Frattura ed Integrità Strutturale, 35, 523-533.

6 Calì, C. and Citarella, R. (2004) Residual strength assessment for a butt joint in MSD condition. Advances in Engineering Software, 35, 373-382.

7 Sepe, R., Armentani, E. and Caputo, F. (2016) Static and fatigue experimental tests on a full scale fuselage panel and FEM analyses. Frattura ed Integrità Strutturale, 10, 534-550.

8 Sepe, R., Armentani, E., Lamanna, G. and Caputo, F. (2015) Fatigue behaviour of full scale flat stiffened aeronautic panels. Key Engineering Materials, 627, 97-100.

9 Sepe, R., Armentani, E., Di Lascio, P. and Citarella, R. (2015) Crack growth behaviour of welded stiffened panel. Production Engineering, 109, 473-483.

10 Citarella, R. and Apicella, A. (2006) Advanced design concepts and maintenance by integrated risk evaluation for aerostructures. Struct. Durability Health Monit., 2, 183-196.

11 Zentech International Limited (2016) ZENCRACK manual, version 7.9. http://www.zentech.co.uk/Zencrack_support_version79.htm

12 Citarella, R., Lepore, M., Shlyannikov, V. and Yarullin, R. (2014) Fatigue surface crack growth in cylindrical specimen under combined loading. Engineering Fracture Mechanics, 131, 439-453.

13 Citarella, R., Lepore, M., Maligno, A. and Shlyannikov, V. (2015) FEM simulation of a crack propagation in a round bar under combined tension and torsion fatigue loading. Frattura ed Integrità Strutturale, 31, 138-147.

14 Citarella, R., Cricrì, G., Lepore, M. and Perrella, M. (2014) Thermo-mechanical crack propagation in aircraft engine vane by coupled FEM-DBEM approach. Advances in Engineering Software, 67, 57-69.

15 Willenborg, J., Engle, R.M., Wood, H.A. (1971) A crack growth retardation model using an effective stress concept. Report no.
AFFDL-TR71-1. Air Force Flight Dynamic Laboratory. Wright-Patterson Air Force Base, USA.

16 Wheeler, O. E. (1972) Spectrum loading and crack growth. Journal of Basic Engineering, 94, 181-186.

17 Pereira, M. V. S., Darwish, F. A. I., Camarãoc, A. F. and S. H. M. (2007) On the prediction of fatigue crack retardation using Wheeler and Willenborg models. Materials Research, 10, 101-107.

18 Carlone, P., Citarella, R., Sonne, M. R. and Hattel, J. H. (2016) Multiple crack growth prediction in AA2024-T3 friction stir welded joints, including manufacturing effects. International Fournal of Fatigue, 90, 69-77.

19 Citarella, R., Carlone, P., Lepore, M. and Sepe, R. (2016) Hybrid technique to assess the fatigue performance of multiple cracked FSW joints. Engineering Fracture Mechanics, 162, 38-50.

20 Citarella, R., Carlone, P., Sepe, R. and Lepore, M. (2016) DBEM crack propagation in friction stir welded aluminum joints. Advances in Engineering Software, 101, 50-59.

21 Carlone, P., Citarella, R., Lepore, M. and Palazzo, G. S. (2015) A FEM-DBEM investigation of the influence of process parameters on crack growth in aluminium friction stir welded butt joints, Int. 7. Mater. Form., 8, 591-599.

22 Citarella, R., Carlone, P., Lepore, M. and Palazzo, G. S. (2015) Numerical-experimental crack growth analysis in AA2024-T3 FSWed butt joints. Advances in Engineering Software, 80, 47-57.

23 Citarella, R., Lepore, M., Perrella, M., Sepe, R. and Cricrì, G. (2016) Coupled FEM-DBEM simulation of 3D crack growth under fatigue load spectrum. Struct. Integrity Procedia, 2, 2631-2642.

24 Heulera, P. and Klatschkeb, H. (2005) Generation and use of standardised load spectra and load-time histories. International Journal of Fatigue, 27, 974-990. 